\title{
Corpus
}

Archivos virtuales de la alteridad americana

Vol 4, No 2 2014

Julio / Diciembre 2014

\section{¿Vivir entre dos mundos? Parentesco y política en la vida de José Valdebenito, "Encargado de los Indios" en Cruz de Guerra (1830-1859)}

Living between two worlds? Kinship and politics in José Valdebenito's life, "Encargado de los indios" [In charge of the Indians] at Cruz de Guerra (1830-1859)

\section{Luciano Literas}

\section{(2) OpenEdition}

\section{Journals}

\section{Electronic version}

URL: http://journals.openedition.org/corpusarchivos/1218

DOI: 10.4000/corpusarchivos.1218

ISSN: 1853-8037

\section{Publisher}

Diego Escolar

\section{Electronic reference}

Luciano Literas, "¿Vivir entre dos mundos? Parentesco y política en la vida de José Valdebenito, "Encargado de los Indios" en Cruz de Guerra (1830-1859) », Corpus [En línea], Vol 4, No 2 | 2014 ,

Publicado el 19 diciembre 2014, consultado el 01 mayo 2019. URL : http://journals.openedition.org/ corpusarchivos/1218; DOI : 10.4000/corpusarchivos.1218

This text was automatically generated on 1 May 2019.

Licencia Creative Commons: Atribución-NoComercial 2.5 Argentina (CC BY-NC 2.5 AR) 
¿Vivir entre dos mundos? Parentesco y política en la vida de José Valdebenito, "Encargado de los Indios" en Cruz de Guerra $(1830-1859)^{1}$

Living between two worlds? Kinship and politics in José Valdebenito's life, "Encargado de los indios" [In charge of the Indians] at Cruz de Guerra (1830-1859)

Luciano Literas

\section{EDITOR'S NOTE}

Fecha de recepción del original: 06/08/2014

Fecha de aceptación para publicación: 27/11/2014

\section{Introducción}

1 Su apellido es tan difuso y equívoco como su identidad. Benito Valdez, Valdebenítez, Balde Benito y Baldevenites son algunas de las variaciones ofrecidas por las escasas y heterogéneas fuentes documentales que evocan su persona. 0 también la más frecuente en los registros militares y de tierras: Valdebenito.

2 José Valdebenito fue miembro de la montonera realista de los hermanos Pincheira que combatió a los patriotas chilenos durante la "guerra a muerte" (1819-1832). Posteriormente migró con los borogas al paraje pampeano de Guaminí, donde negociaron la paz con el gobierno de Buenos Aires de Juan Manuel de Rosas (1830). Se incorporó al 
ejército porteño en calidad de alférez y ejerció de lenguaraz entre Rosas y la junta de caciques presidida por Juan Ignacio Cañuquir y Mariano Rondeau. Tras la muerte del último (1834), Valdebenito participó en la diáspora y migración boroga a jurisdicción estatal -en Cruz de Guerra y Mulitas, orígenes del partido bonaerense Veinticinco de Mayo- (Literas 2014).

3 Los servicios al gobierno de Buenos Aires y el parentesco con los descendientes de Rondeau le valieron un notable ascenso en la administración militar local así como una inigualable ascendencia personal y política entre los borogas. Esto no fue alterado por los cambios políticos tras el derrocamiento de Rosas, en 1852. Más bien, una singular ubicuidad reforzó su poder. Hacia el final de su vida velaba por el orden en las zonas rurales y la protección del principal producto de Veinticinco de Mayo -el ganado vacuno y lanar- mientras ejercía el mando militar boroga. El poder que ejerció fue tal que el fuerte que comandaba se trasladó a su propiedad -concedida por el gobierno- y fue rebautizado Fuerte Valdebenito. El 5 de marzo de 1859, en un contexto de álgidos conflictos faccionales e interétnicos, Valdebenito murió. Por entonces era sargento mayor de caballería del ejército de línea, comandante de Veinticinco de Mayo y Encargado de los Indios Amigos. Poco después, Santiago Avendaño no dudó en definirlo como "un bípedo con charreteras sin más títulos que el de ser un cristiano renegado, asqueroso por su convivencia con varias mujeres juntas (indias por cierto), como un cacique en el desierto", un "chileno inmoral" que "al frente de una meritoria tribu de fieles indios" se había transformado en "odioso", acaudalado y todopoderoso personaje local (1999, p. 335).

4 A pesar del protagonismo que tuvo en las fronteras - según los escasos datos biográficos y las apreciaciones de Avendaño- Valdebenito continúa poblando las sombras de la antropología y la historia. El propósito de este trabajo será analizar su trayectoria de vida, ya que consideramos que puede ofrecer valiosos indicios de los actores (Ginzburg 2010a, 2010b), las relaciones y las dinámicas socio-políticas e interétnicas de las fronteras de Pampa y Patagonia, durante una parte significativa del extenso y polémico período de organización estatal postcolonial. Se hará examinando especialmente aquellos aspectos que explican su singular itinerario, en virtud de las agencias indígenas y las políticas estatales que operaron en los espacios donde transcurrió su vida.

5 White (2009) afirmó que el contacto interétnico en América frecuentemente no produjo historias complejas, sino que alternó enfoques que priorizaron la conquista y la asimilación unilateral con la persistencia cultural y la resistencia pretérita. Procurando trascender estas perspectivas, planteó las fronteras como espacios construidos por procesos creativos de negociación y producción de valores, significados y prácticas, en virtud del contacto entre actores de diferentes procedencias e intereses sociopolíticos. A pesar de que esto requirió una cierta aceptación diplomática y cotidiana, como sostuvo Havard (2003), lo anterior no debe llevarnos a desatender las dinámicas más generales de dominación colonial o republicana ni las relaciones de poder subyacentes. Más allá de las divergencias teórico-metodológicas entre los autores que han abordado esta clase de problemas, interesa destacar aquí dos aspectos. En primer lugar, que la situación impuesta por la conquista político-territorial no fue enteramente estéril o destructiva sino que estimuló la invención e improvisación exigidas por la supervivencia y el mantenimiento de la autonomía relativa en contextos de cambio y desconcierto (Gruzinski 2007). En segundo lugar, que a raíz de estas transformaciones de los actores, de sus comportamientos y de las modalidades de interacción es que se ha definido a las 
fronteras como espacios transicionales (Boccara 2003). Por ejemplo, en diferentes ámbitos americanos se insistió en la influencia que tuvieron la agencia social y la experiencia interétnica en las rearticulaciones y reformulaciones de identidades, ofreciendo márgenes de autonomía y negociación (Álvarez 2011; Celestino de Almeida 2012). En Pampa y Patagonia la complejidad heurística vino de la mano de estudios que asociaron las fronteras con la construcción del orden político argentino, constituyendo ámbitos inestables, permeables y fluidos de interacción, donde se ensayaron mixturas en las que muchos conceptos cobraron nuevos sentidos y donde no fue fácil distinguir la guerra y la paz, lo blanco y lo indio, el consenso y la imposición (Gregorio-Cernadas 1998; Bechis 2010, Quijada 2011).

6 Junto a la frontera, el mestizaje es otro concepto íntimamente asociado a la trayectoria de Valdevenito. Este ha sido un concepto problemático cada vez que presupuso purezas biológicas o entidades culturales prístinas, dotadas de contornos tangibles y estables, y con capacidad de influir unívocamente en los comportamientos individuales (Stolcke 2006). En las fronteras el mestizaje alude más al encuentro de fenómenos y lógicas tan heterogéneas como dinámicas, que redefinieron y recrearon relaciones a partir de fuentes y trayectorias múltiples. Las fronteras no fueron líneas infranqueables entre mundos impermeables. Apelando a una conocida metáfora, podemos decir que lejos estuvieron de semejar una mesa de billar donde las bolas solo podían chocar una y otra vez conservando sus respectivas homogeneidades, diferencias y límites (Wolf 2005). Valdebenito en particular y los intermediarios político-culturales en general son ejemplo de ello. Personas para quienes las fronteras más que límites de separación fueron vías (pathways) y que al disponer de capitales políticos y culturales relevantes en las estructuras de poder ejercieron habilidades comunicativas, roles sociopolíticos y conocimientos distintivos en la interacción interétnica (Szasz 1994). Esta intermediación no se construyó y ejerció en un plano de igualdad; más bien se hizo sobre la presunción de la dependencia y la irrevocabilidad del proceso (Ronda 1994).

7 Numerosos estudios abordaron la vida de diferentes intermediarios en Pampa y Patagonia: lenguaraces, escribientes, caciques, cautivos, agregados, aindiados y autoridades fronterizas del Estado. Aunque de disímiles modos, todos habitaron las fronteras y sirvieron de nexo entre dos mundos (Villar y Jiménez 1997; Ortelli 2000; Ratto 2005a; Madrini 2006; De Jong 2008). Específicamente en Guaminí hubo quienes se detuvieron en un compañero de armas de Valdebenito: Pablo Millalicán. Un boroga criado en el Colegio de Naturales de Chillán, que a pesar de haber sido oficial de las fuerzas patriotas durante la independencia chilena, después fue escribiente de la junta de caciques e incorporado al ejército porteño como teniente de caballería (Pavez Ojeda 2008; Bechis 2010). Al igual que Valdebenito, fue ineludible en los itinerarios indígenas en las fronteras. Incluso tras la muerte de Rondeau y la diáspora de Guaminí, Millalicán continuó ejerciendo de intermediario político-cultural de Juan Calfucurá. También existen estudios sobre quien -como Millalicán- muy probablemente primero fue adversario y después camarada de Valdebenito: Francisco Iturra (Rojas Lagarde 2013). A diferencia de Valdebenito, fue un militar patriota, pero al igual que él llegó desde Chile durante la "guerra a muerte" y se incorporó a las fuerzas porteñas como intermediario de los caciques de Pampa y Patagonia en calidad de alférez y lenguaraz en la Fortaleza Protectora Argentina. Ambos encuadran en la pertinente definición de "aindiados" (Villar y Jiménez 2003): aquellos miembros de las fuerzas realistas o patriotas que tras participar de las beligerancias militares revolucionarias en el margen occidental de la cordillera de 
los Andes se insertaron en distintas parcialidades indígenas, conservando los rangos militares, aprendiendo y utilizando sus lenguas y participando de sus modos de vida.

\section{Un montonero realista devenido en lenguaraz boroga}

Valdebenito encarnó las interacciones políticas y militares entre la sociedad criolla rioplatense y los grupos indígenas de Pampa y Patagonia a lo largo de tres décadas, signadas por la desarticulación del poder colonial, la polémica construcción del novel orden político, la progresiva y dificultosa disolución de las "fronteras interiores" así como la especialización ganadera de las llanuras pampeanas. Sin embargo, el punto de partida de su trayectoria político-militar reside en el margen occidental de los Andes, durante el avance estatal postcolonial hacia el sur de la actual república chilena.

El primer acontecimiento en que enmarcamos la vida de Valdebenito son las beligerancias cívico-militares que siguieron a la independencia de Chile. Estas fueron conocidas como "guerra a muerte" y deben situarse en el contexto más amplio de la "década ominosa", en que Fernando VII promovió la restauración antiliberal en la península ibérica y América. En la Araucanía hubo especial apoyo a la resistencia realista, protagonizada por diversas montoneras rurales de extracción hispana, criolla e indígena -muchas veces con el sostén del clero y la oficialidad militar colonial- (Manara 2010; Rojas Lagarde 2013). José Antonio y sus hermanos Antonio, Santos y Pablo Pincheira dirigieron una de las más relevantes. Eran hijos de Martín Pincheira, capataz y soldado del ejército colonial, vecino de la zona de Chillán con ascendencia en la población local y fluidos contactos con varios caciques (Manara 2010). Ante las derrotas militares y la disminución del apoyo español, los Pincheira abandonaron Chile junto a habitantes de Boroa, en Cautín (Ratto 2005b). Promediando la década de 1820 habitaban Guaminí, procurando controlar puntos estratégicos de los itinerarios sociales y comerciales a la cordillera. Uno de estos montoneros pincheiranos era Valdebenito, y entre los caciques se encontraba quien poco después cambiaría su nombre por el de Rondeau. Por entonces, la Pampa se transformaba en pieza clave del sostenimiento del nuevo orden político en Buenos Aires. El colapso del sistema comercial colonial que había hecho de la ciudad porteña un eslabón relevante del tráfico de bienes del Alto Perú, Paraguay y las provincias mediterráneas, así como la destrucción de los espacios ganaderos del litoral por las guerras civiles postcoloniales, hicieron que Buenos Aires dirigiera la atención a la Pampa para garantizarse ingresos a través de la capitalización agrícola-ganadera (Barsky y Djenderedjian 2003; Infesta 2006; Garavaglia 2009).

Desde el asentamiento en Guaminí, borogas y rebeldes pincheiranos alternaron parlamentos de paz y beligerancias con el gobierno porteño. Guaminí ${ }_{\text {se transformó en un espacio }}$ de fluido contacto entre las autoridades político-militares porteñas y la población boroga. Un intersticio entre los territorios de jurisdicción estatal y las extensiones de "tierra adentro", pobladas por personas aún no sujetas que controlaban importantes itinerarios y extensiones de pastoreo ganadero. Esto ocurrió en el marco del "negocio pacífico de indios", puntal de la política fronteriza de Buenos Aires durante el gobierno de Rosas -que gobernó casi ininterrumpidamente desde 1829 a 1852-. Fue un sistema de tratados interétnicos en función de vínculos personales con Rosas y de tipo verbal, que contempló la entrega de bienes de uso y consumo por parte del gobierno porteño a cambio de prestaciones militares, políticas y diplomáticas (Ratto 2003, 2007). En él se inscribió la relación de los borogas con Buenos Aires y allí es donde Valdebenito aparece por primera vez en las fuentes. 
11 Al Tratado de Carrizal acordado en 1829 por los Pincheira y el gobierno de Mendoza, le siguió la desarticulación de la montonera y en 1832 la captura de José Antonio Pincheira a manos del militar chileno Manuel Bulnes, en territorio de Neuquén (Manara 2010)². Mientras tanto, algunos montoneros se unieron a Buenos Aires, entre ellos Valdebenito. El gobierno porteño le otorgó el título de alférez del ejército - un grado menor aunque usual inicio de carrera en la oficialidad-y comenzó a ejercer como lenguaraz de la junta de caciques en Guaminí. Al igual que lo ocurrido posteriormente con los caciques y capitanejos de las tribus de indios amigos, la incorporación a la administración militar fronteriza reconoció y reforzó el capital social y político de Valdebenito.

12 En 1830 el gobernador de Buenos Aires y la junta de caciques acordaron la paz ${ }^{3}$. Como veremos, de ahí en adelante las pautas de la interacción interétnica serían motivo de conflictos y desencuentros. Unos y otros reclamarían en función de sus propios intereses. El gobernador, a favor de la devolución de cautivas, el fin de los malones, la ruptura con los ranqueles, el auxilio militar y la férrea lealtad política. La junta de caciques lo haría en favor de la protección estatal, el suministro de bienes de uso y consumo y el permiso para comerciar plata, sal y tejidos en territorio provincial.

\section{Lenguaraz y alférez: la vida entre Guaminí y Buenos Aires}

13 Desde 1830 y hasta la diáspora boroga en Guaminí, entre 1834 y 1835, Valdebenito ejerció simultáneamente de alférez del ejército de Buenos Aires y lenguaraz de la junta de caciques. Por entonces, participó de la expedición comandada por Rosas en 1833 que extendió sustancialmente la frontera estatal hacia el sur. Desconocemos el papel de Valdebenito en esta incursión, así como de los borogas de Guaminí. Sin embargo, el

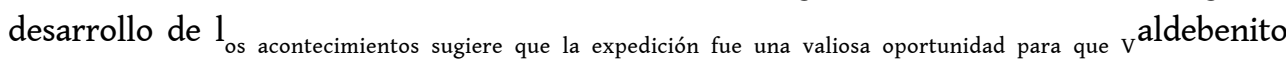
explicitara su lealtad a Buenos Aires y construyera relaciones en la administración militar que lo había acogido recientemente.

14 Simultáneamente, Valdebenito explotó y potenció sus vínculos con los borogas y el dominio del mapundungun. En pocos años se convirtió en protagonista relevante del "negocio pacífico de indios" no solo como alférez y lenguaraz sino también como miembro de las comisiones que llevaban los auxilios de bienes de consumo y de uso a Guaminí. Al respecto, se ha asociado el poder o la relevancia de los lenguaraces durante los contactos interétnicos en virtud de la centralidad - por momentos excluyente- de la oralidad en las organizaciones sociopolíticas de Pampa y Patagonia (Gregorio-Cernadas 1998; Pérez Zavala 2005). De ahí los problemas teórico-metodológicos que conlleva limitar el análisis de las negociaciones interétnicas a lo indicado textualmente en las actas, informes o correspondencias (Roulet 2004). También se han mencionado ciertas estrategias empleadas por los caciques -sobre todo si no hablaban ni escribían castellano - para contrarrestar el poder de los lenguaraces y escribientes (Bechis 2008; Pavez Ojeda 2008). Muy probablemente los caciques de Guaminí no escribían castellano -el escribiente, como vimos, era Millalicán- pero desconocemos si lo hablaban. Aun así la presencia de Millalicán no mermó el poder de Valdebenito, asociado no solo a la lengua sino a la capacidad de trasladarse entre la residencia del gobernador y las tolderías, como pieza clave del "negocio pacífico de indios". Por entonces disponía, además, de los valiosos pasaportes que el gobierno emitía para permitir los desplazamientos borogas en 
la campaña con propósitos comerciales. Uno de los documentos que mejor ilustra el funcionamiento de este sistema interétnico, el tipo de vínculos que fijó y la posición intermedia de Valdebenito, es una carta que Rondeau a través de Millalicán escribió al teniente coronel Miguel Miranda, el 7 de octubre de 1833, desde Guaminí.

Mi amigo y cuñado: acordandome de nuestros cariños y vuena amistad; paso a decirle a Ud. me haga el favor de mandarme algunas cosas, de regalo, en obsequio de la amistad; pues yo, quando Ud. estuvo aquí entre nosotros, siempre fui generoso con Ud.; nunca fui escaso [...] Haora que vamos hacerles honras y sacrificios á Dios, para que nos ayude conservar la verdadera paz, el reposo y tranquilidad. Y juntamente para que nos de victorias y triunfos contra ntros. enemigos. Necesito varias cosas, por eso le escrivo $\mathrm{p}^{\mathrm{a}} \mathrm{q}^{\mathrm{e}}$ me haga el favor de mandarme algunas cosas, lo que Ud. tuviese a vien de mandarme con mi Lengua José Baldevenito. ${ }^{4}$

El "negocio pacífico de indios" implicó el ajuste de ciertas prácticas borogas. El gobierno de Buenos Aires insistentemente solicitó a los caciques que las censuraran y penalizaran, poniendo en juego la segmentalidad sociopolítica boroga. Esto fue la recurrente alternancia de procesos de unión (fusión) y separación (fisión) de segmentos o linajes relativamente autosuficientes, en virtud de la inexistencia de instituciones políticas y mecanismos coercitivos que garantizaran la unidad -y su liderazgo legítimo- más allá del parentesco y la contigüidad (Bechis 2005). Las razones que motivaron la unión o separación de segmentos fueron heterogéneas. En este caso debemos considerar los conflictos desencadenados a partir de las reiteradas solicitudes de devolver cautivas, la prohibición de malonear y arrear ganado desde la frontera, el pedido de ruptura de los lazos -en ocasiones de parentesco- con los ranqueles y el auxilio militar en las incursiones contra otras tribus. Esto desencadenó diferencias al interior de la junta de caciques y puso de manifiesto el limitado poder que ejercían sobre los toldos (Ratto 2005b). Aquí radicó el carácter trágico del itinerario boroga en Guaminí.

El enfrenamiento inicial fue entre Cañuquir y Rondeau. El primero ejercía de cacique principal de la junta y siempre tuvo una posición ambigua y carente de confianza para Buenos Aires. El segundo fue más proclive a aplicar las solicitudes de Rosas y paulatinamente desplazó a Cañuquir de las negociaciones. Más allá de estas diferencias, Valdebenito continuó ejerciendo de lenguaraz. Incluso en períodos de distanciamiento entre Buenos Aires y Guaminí a causa del incumplimiento de lo acordado en el marco del "negocio pacífico de indios", valdebenito fue clave. Es más, quizás sus prerrogativas aumentaron al persistir como uno de los escasos vínculos entre las tolderías borogas y la residencia del gobernador. En febrero de 1834, mediante la pluma de Millalicán, la junta de caciques de Guaminí escribió a Rosas:

Quando hay algunas faltas entre amigos y aliados, es muy justo de que se haga saber los sentimientos, cómo y de que modo sean dimanados, quando nosotros esperavamos con tantas ansias y desvelos sus generosas expresiones, hasta haora no hemos tenido el merecimiento de Recibirle sus consolativas palabras, desde que se vino Quicham y el Lengua Baldevenito [...] Es muy verdad Sor. Excmo. que hablamos algunas pesades ${ }^{s}$ quando volbio Quicham con Baldevenito, de ver que nos pedian mas cautivas y cautivos, sin darnos algun alibio". 5

17 A los pocos días, Valdebenito acompanó a Rondeau a reunirse -quizás ${ }^{6}{ }^{6}$ Unos meses después, en septiembre de 1834 , Rondeau fue asesinado junto al cacique Melin. Las razones y circunstancias de su muerte aún son controvertidas y trascienden los propósitos de este trabajo. Como ha sugerido Ratto (2005b), muy probablemente tuvo una gravitación significativa el conflicto al interior de la junta de caciques y el rechazo de los borogas a que Rondeau aprovechando su relación más próxima con Rosas- sustituyera a Cañuquir y al resto de caciques en las negociaciones con Buenos Aires. Lo que interesa destacar aquí, sin 
embargo, es que este hecho dio lugar a una mayor presión estatal para que los caciques ejercieran una autoridad diferente a la que ejercían, acelerando la separación y diáspora de las tolderías en Guaminí. Tras morir Rondeau, otro miembro de la junta de caciques, Caneullan, aceptó la invitación de asentarse bajo jurisdiccional provincial, en los alrededores del fuerte Mayo, en la laguna Cruz de Guerra. A lo largo de 1835, otras cabezas de toldo como Guayquil y Alón siguieron sus pasos. En 1836, Cañuquir fue asesinado por

fuerzas de Buenos Aires en Guaminí.

18 A pesar de la muerte de Rondeau, Valdebenito continuó como alférez comisionado en Guaminí, viajando entre este paraje, Buenos Aires y la residencia del gobernador con comunicaciones, auxilios, animales y acompañando a borogas en desplazamientos diplomáticos ${ }^{\circ} \mathrm{Al}$ menos desde entonces fue parte de la Plana Mayor Activa del ejército porteño ${ }^{7} \mathrm{y}$ su papel iba más allá de simple conductor de correspondencia o de bienes. Personalmente transmitía a Rosas las noticias acaecidas en las fronteras, así como las demandas que este hacía a los caciques de devolver cautivos y apurar las acciones contra aquellos no incluidos en el "negocio pacífico de indios".

Hasta entonces el contacto interétnico había revelado una cierta improvisación e indecisión, gobernaban plenamente. Sin embargo, la diáspora de los toldos y el asentamiento de una parte significativa de la población boroga bajo la órbita estatal en Cruz de Guerra, cambió radicalmente la situación. Esto también repercutió en la situación de Valdebenito.

\section{"Encargado de los Indios" en Cruz de Guerra}

Las comisiones en Guaminí le valieron a Valdebenito ser designado en 1847 al mando del fuerte de Cruz de Guerra, donde servían en las armas los borogas junto a criollos regulares y milicianos (Thill y Puigdomenech 2003; Literas 2014). Por entonces el gobierno había premiado sus acciones al frente de los borogas en la protección de ese paraje, combatiendo malones de tribus enemigas de Buenos Aires . En los años que siguieron, Valdebenito ascendió en la estructura militar local hasta ser designado sargento mayor "Encargado de los Indios" 9 . A la hora de explicar este asenso debemos considerar antes que nada su relación con los borogas. Las escasas fuentes confirman que su papel de lenguaraz se transformó en liderazgo militar.

El servicio de armas boroga en Cruz de Guerra, además de una obligación y un salario comportó reconocimiento social e incluso determinadas formas de prestigio. Quijada (2011) ha indicado que muchos de los signos asociados a la organización y funcionamiento de estas prestaciones militares -como los grados, uniformes y discursos- pudieron ser apropiados con interés por los borogas, al proyectar públicamente su protagonismo en las fronteras. Si tenemos en cuenta que Valdebenito estuvo al mando de los borogas y del fuerte donde cumplían servicio, damos con una primera razón de su ascendencia. El servicio de armas no solo fue un mecanismo de incorporación estatal - un dispositivo de poder- sino también un espacio de negociación y acomodamiento. Otorgó cierta autonomía relativa así como rangos oficiales, hechos que apoyan la hipótesis de una nada despreciable aceptación del servicio y su uso estratégico por parte de los borogas. Además, como se ha indicado en otro lugar, a diferencia de las fuerzas criollas regulares y milicianas aún no se han hallado fuentes sobre episodios de deserción o sublevaciones 
borogas de Cruz de Guerra, más allá de la sublevación de Cristóbal Carri-llang que abordaremos más adelante (Literas 2014).

La otra clave para explicar la ascendencia de Valdebenito proviene del parentesco. Desconocemos aún la fecha y la forma, pero Valdebenito fue cónyuge de una de las hijas del extinto cacique Rondeau y de María Mareus, probablemente Felipa Rondeau. Según las crónicas tradicionales, al morir Rondeau, Mareus y sus hijos migraron a Cruz de Guerra siguiendo los pasos de Caneullan. Los hermanos de Felipa eran Martín, Francisco, Manuel y Ana. Como veremos a continuación esta unión cimentó un vínculo que conllevó compromisos y obligaciones que trascendieron ampliamente las disputas y los conflictos faccionales característicos de las diferentes coyunturas históricas. Una unión vinculada a la construcción de redes sociales y relaciones de poder que fueron más allá de los comportamientos políticos y militares, incluyendo por ejemplo, el acceso y uso de la tierra (Literas y Barbuto 2014).

\section{Valdebenito ante los nuevos tiempos}

El derrocamiento de Rosas en febrero de 1852 inició una década de conflictos y beligerancias por el poder político en Buenos Aires y el conjunto de la república. Esto, sin embargo, no implicó cambios sustanciales en la situación de Valdebenito. La nueva elite política porteña cambió el nombre de Mulitas por Veinticinco de Mayo, modificó aspectos simbólicos y organizativos de la administración militar, sustituyó las fuerzas regulares y milicianas por nuevas instituciones y reemplazó numerosas autoridades locales y provinciales. Sin embargo, el chileno con veinte años de servicio en la administración militar rosista conservó su rango y nada fue modificado en relación al servicio que los borogas cumplían bajo su mando. Es más, al cabo de un año y en reconocimiento de sus "relevantes servicios" Valdebenito fue ascendido de capitán a sargento mayor de caballería de línea ${ }^{10}$.

Como se adelantó en la introducción, Avendaño (1999) describió a Valdebenito como una autoridad todo poderosa en el ámbito local, más parecido a un cacique que a un militar criollo, propietario de una fortuna vinculada al robo de ganado que tenía la obligación de proteger. Avendaño le dedicó varias páginas de sus memorias, otro indicio de la importancia de Valdebenito en la campaña bonaerense. Quien había cautivado a Avendaño, Caniu-Calquim, le había advertido que como lenguaraz se alejara del poco ejemplar comportamiento de Valdebenito, a quien definía como "chileno bruto y perverso [...] todo porque sabía la lengua mapuche; sin más que por eso es ahora un gran rico" (en Bechis 2008, p. 376) ${ }^{11}$. No solo la pluma de Avendaño habló de Valdebenito. El cacique por entonces más poderoso de Pampa y Patagonia, Juan Calfucurá, reprochó al gobernador de Buenos Aires el ensañamiento de Valdebenito con los chasques que interceptaba, que ejerciera sus funciones en Veinticinco de Mayo "haciendo barullo, animando a la gente a pelear" así como su reprochable actuación en la avanzada sobre los toldos de Juan Manuel Cachul, en Azul, donde "hicieron pedazos a las mujeres, matándolas como ovejas" (Rojas Lagarde 2013, p. 122) ${ }^{12}$. En sus comunicaciones, Calfucurá insistió una y otra vez que las acciones de Valdebenito perjudicaban la paz.

Calfucurá había adquirido una notable relevancia sociopolítica en las fronteras del Estado argentino. Asentado en Salinas Grandes desde hacía más de dos décadas y antiguo aliado de Rosas, había fortalecido su liderazgo controlando circuitos ganaderos, tejiendo 
numerosas alianzas con otros líderes indígenas y transformándose en importante receptor y distribuidor de bienes recibidos en el marco del "negocio pacífico de indios" (De Jong y Ratto 2008; De Jong 2011). Ante la caída del régimen rosista, la desarticulación del sistema de acuerdos interétnicos, la sustitución de muchas de las autoridades fronterizas así como la tentativa porteña de avanzar las fronteras estatales, Calfucurá se alió a la Confederación de provincias liderada por Justo José de Urquiza, en conflicto con el nuevo gobierno de Buenos Aires. En el contexto que se abría -signado por álgidas luchas faccionales, volubles y cambiantes realineamientos, alianzas y connivencias políticas- resultó crucial la influencia política de las autoridades político-militares con duraderas relaciones interpersonales con los borogas. La ascendencia de Valdebenito entre los borogas de Veinticinco de Mayo es una variable ineludible para entender el alineamiento de la mayoría de ellos con Buenos Aires. Valdebenito no dudó en mantenerse siempre leal al gobierno porteño -más allá de quien lo presidiera-y a cambio de ello, su liderazgo fue reforzado.

$\mathrm{Al}$ año siguiente del acuerdo entre Calfucurá y Urquiza, en 1856, Cristóbal Carri-llang (el indio Cristo) sargento de Caneullan, abandonó Veinticinco de Mayo junto a una treintena de borogas, protagonizando la única sublevación en la tribu revelada hasta ahora por las fuentes. De inmediato las familias y haciendas de los sublevados fueron retenidas por Valdebenito. Más allá de ciertos matices, dos cronistas contemporáneos atribuyeron las razones del episodio a las diferencias de Carri-llang con Valdebenito (Avendaño 1999; Curiel 1898). Molesto el último por la creciente ascendencia de Carri-llang sobre los borogas, habría difundido falsos rumores sobre relaciones subrepticias con Calfucurá. Las quejas de Carri-llang por los recurrentes problemas de racionamiento a raíz de los oscuros negocios de Valdebenito, no habrían hecho más que aumentar la tensión ${ }^{13}$. De modo que la sublevación de Carri-llang pudo haber sido motivada por la ambición de Valdebenito de conservar un liderazgo indiscutido de los borogas. Tras este episodio, Carri-llang avanzó sobre Veinticinco de Mayo reiteradamente, siempre con el apoyo de Calfucurá y la Confederación (Literas 2014) ${ }^{14}$. Frecuentemente estas avanzadas tuvieron como objetivo saquear la zona donde Valdebenito y los Rondeau tenían sus poblaciones rurales. Como afirmó un alto oficial porteño, los ataques se debían a disputas personales más que a las beligerancias faccionales entre Buenos Aires y la Confederación ${ }^{15}$; prueba del peso que tenían las relaciones interpersonales entre caciques y autoridades políticas y militares en los conflictos post-rosistas.

En 1857 el Ministerio de Guerra y Marina designó a Valdebenito comandante de Veinticinco de Mayo, máximo rango que ofrecía la administración militar local ${ }^{16}$. Por entonces, el fuerte Cruz de Guerra fue trasladado a las tierras que el gobierno provincial le había concedido en virtud de sus servicios y fue rebautizado Cruz de Guerra Nueva o Fuerte Valdebenito. Simultáneamente, si observamos la evolución de las listas de revista del piquete de servicio de armas boroga, los Rondeau aumentaron progresivamente sus prerrogativas al interior de la tribu, ascendiendo con joven edad a los rangos militares indígenas más altos (Literas 2014).

28 Es escasa la información que ofrecen las fuentes sobre los dos últimos años de vida de Valdebenito. En una carta de 1858, Calfucurá informó que ranqueles bajo las órdenes del coronel Manuel Baigorria "llevan a Baldebenitez derrotao y le han quitado dos cañones y muerto mucha gente" (Rojas Lagarde 2013:148). Sin embargo, esto no aparece en otros documentos ni existen registros sobre la captura de Valdebenito. En la portada de una de las listas de revista militar de Veinticinco de Mayo de 1859, una nota improvisada señaló escuetamente que el "Sarg to. or. n. ${ }^{\mathrm{n}}$ José Valde Benitez falleció en 5 de marzo" ${ }^{17}$. Quien escribió la nota se corrigió así 
mismo. Había comenzado a escribir el apellido con B en lugar de V. Finalizaba la década de 1850, crucial en la definición del orden político argentino y decisiva en la construcción de liderazgos en la tribu de Rondeau y el partido de Veinticinco de Mayo.

\section{El acceso a la tierra: armas y parentesco}

29 Al morir Valdebenito, los hermanos Rondeau completaron su ascenso en la estructura militar local al ser designados al mando de la tribu. Martín Rondeau fue nombrado teniente primero de caballería y sustituyó a Mariano Teuque como cacique principal (Literas 2014). Francisco Rondeau por entonces revistaba con el rango de alférez secundando a Martín en el mando- y Manuel Rondeau obtuvo el grado de sargento (Hux 2004). Desde entonces y hasta que el servicio de armas boroga concluyó a inicios de la década de 1870, los Rondeau se mantuvieron en las posiciones militares indígenas más relevantes ¿En qué medida los vínculos con Valdebenito les habían valido en las negociaciones e interacciones con las autoridades político-militares del Estado? Probablemente en la misma medida que al oficial chileno para mantener y aumentar su ascendencia entre los borogas y de cara al resto de autoridades estatales.

Por entonces el gobierno de Buenos Aires donó leguas de tierra a numerosas tribus de indios amigos: de Coliqueo en Los Toldos, Raylef y Melinao en Bragado, Raninqueo en Bolívar y Ancalao en Bahía Blanca, por ejemplo. Esto se realizó mediante donación a los caciques "y sus tribus". Los discursos de las elites políticas avalaron esta política en la necesidad de garantizar la sedentarización indígena y promover la colonización agrícolaganadera de las fronteras, combinando el reconocimiento del arraigo de estas poblaciones y su lealtad política. No obstante, en el caso de los Rondeau la donación difícilmente puede explicarse sin el parentesco y la estrecha relación con el difunto Valdebenito (Literas y Barbuto 2014).

Uno de los hechos que ilustra la relevancia del parentesco y el servicio de armas en las dinámicas políticas de la frontera es que los Rondeau fueran herederos de Valdebenito a raíz del vínculo de este con una de sus hermanas. Como vimos, en reconocimiento a los servicios en las fronteras, el gobierno de Buenos Aires había concedido tierras al oficial chileno allí donde se erigió el fuerte Cruz de Guerra Nueva o Fuerte Valdebenito. Cuando el gobierno reordenó las adjudicaciones de tierras en el partido al mensurar y dar en arrendamiento los campos de Ford y Baudrix, Valdebenito había muerto. Por esta razón el gobierno extendió la adjudicación a sus herederos, definición que incluyó a los Rondeau y especialmente a su cuñado y albaceas, Martín Rondeau ${ }^{18}$. Sin embargo, a poco de morir, las tierras y pertenencias de Valdebenito habían sido adquiridas por el vecino Manuel Ghiraldo ${ }^{19}$. Con respecto a los inventarios testamentarios de otros vecinos, es llamativa la austeridad de bienes relevados en su establecimiento rural: una casa de paja rodeada de foso y tapias, algunas tablas y vigas de madera, tres corrales para hacienda y un potrero zanjado. El mayor valor de la propiedad radicaba en el monte: más de dieciséis mil plantas de álamos, sauces y duraznos.

Una disputa entre los Rondeau y otros herederos de Valdebenito imposibilitaron que la sucesión fructificara. Sin embargo, ante la insistencia de los hermanos Rondeau para hacerla efectiva, las cámaras parlamentarias bonaerenses resolvieron otorgarla en calidad de donación a los caciques "y su tribu" ${ }^{20}$. Este hecho ilustró más que ningún otro la importancia del parentesco interétnico y las redes sociopolíticas en el acceso y uso del 
espacio. La unión de Valdebenito y Felipa Rondeau permitió a los hermanos Rondeau acceder a la donación de cuatro leguas de tierra, que desde entonces fueron denominadas indistintamente de la tribu de Rondeau y de los herederos de Valdebenito.

\section{Conclusiones}

¿Vivir entre dos mundos? es la pregunta que intitula este trabajo. A pesar de que carece ya de cierta originalidad, continúa siendo pertinente para aproximarnos a los actores, las relaciones y las dinámicas sociopolíticas e interétnicas que intervinieron en las fronteras durante el siglo XIX. De hecho, José Valdebenito vivió entre dos mundos y por ello encarnó las complejas intersecciones entre las políticas estatales y las agencias indígenas, razón del poder que ejerció hasta su muerte así como de su decidido protagonismo en la paulatina disolución de las fronteras. Esto conduce además a reflexionar si es posible abordar estas políticas y agencias por separado. La vida de este montonero realista de origen chileno, protagonista ineludible de la incorporación boroga a la sociedad estatal argentina en construcción, sugiere que ${ }_{\text {no. }}$.

Guaminí fue donde criollos y borogas entraron en contacto e intercambio, pretendiendo imponer sus respectivas reglas y pautas de conducta. Unos lo hicieron a través del "negocio pacífico de indios", otros procurando conservar márgenes de autonomía ante el avance de las fronteras estatales. No fue una relación entre iguales y subyació la vocación del gobierno porteño de conquistar los territorios más australes del continente. Fue una situación condenada a desaparecer más pronto que tarde y que forjaría los comienzos de Valdebenito en la administración militar fronteriza.

Mientras los borogas permanecieron en Guaminí, el cautiverio, el maloneo, las relaciones con los ranqueles y los grupos transcordilleranos fueron permanentes motivos de disputas. En ese contexto jugó un papel clave la negociación no solo de los caciques borogas y las autoridades estatales de la campaña, sino también de otros actores de filiaciones políticas y culturales más difusas, como Valdebenito. Una de las virtudes del exmontonero pincheirano fue tener un pie en cada lado de la comunicación interétnica y las jerarquías político-militares: alférez del ejército porteño y lenguaraz de la junta de caciques. Además, con la capacidad de desplazarse por los diferentes puntos de la campaña bonaerense llevando información, comunicaciones, recursos y personas.

El capital social y simbólico de Valdebenito radicó en ser reclamado por unos y otros como propio, legitimado para obrar por los diferentes y no siempre concurrentes intereses. Fue relevante e imprescindible en el "negocio pacífico de indios" así como para las pretensiones borogas. En qué medida colaboró su condición de "chileno" es aún tema de reflexión. No obstante, es probable que su ubicación en los intersticios de las clasificaciones que articulaban el diálogo interétnico y fronterizo haya favorecido su condición de intermediario político- cultural.

37 A medida que la incorporación boroga en la sociedad estatal se profundizó tras la migración a Cruz de Guerra, el protagonismo de Valdebenito aumentó. La vida en torno a los fortines y pueblos criollos acrecentó los contactos interétnicos, otorgó mayor valor a los recursos político-jurídicos y agudizó la regulación estatal de la vida cotidiana. En todos estos aspectos, Valdebenito resultó clave para los borogas. Ejemplo destacable fue la relativa autonomía que otorgaron a la tribu el servicio de armas y el acceso a la tierra. Además, la presencia boroga en Veinticinco de Mayo en un contexto de luchas 
faccionales, episodios de sublevaciones indígenas y ofensivas sobre la frontera -todo ello durante la desarticulación del "negocio pacífico de indios"- hizo que Valdebenito fuera clave también para el Estado. En un período convulso e inestable, de permanentes y cambiantes realineamientos políticos, garantizar la lealtad de la tribu boroga no era algo menor, y prueba de ello fueron las políticas estatales, especialmente durante la década de 1850. En esta simultaneidad es donde hay que buscar las razones del poder de Valdebenito: la posición que ocupó en las redes y relaciones sociopolíticas vinculadas al liderazgo de la tribu boroga, la administración militar del Estado, los orígenes de Veinticinco de Mayo y el avance de las fronteras criollas sobre Pampa y Patagonia.

\section{BIBLIOGRAPHY}

Álvarez, S. (2011). Parentesco, política y prestigio social en los Pueblos de Indios del partido de Santa Elena. Padrón de 1803. Guayaquil: Museo Los Amantes de Sumpa y Archivo Histórico de Guayas Avendaño, S. (1999 [1879]). Memorias de Santiago Avendaño, ex cautivo de los indios Ranqueles. En M. Hux, Memorias del ex cautivo Santiago Avendaño (pp. 29-359). Buenos Aires: El Elefante Blanco.

Barsky, O., Djenderedjian, J. (2003). La expansión ganadera hasta 1895. Buenos Aires: Siglo XXI.

Bechis, M. (2008 [2000]). Valor y validez de documentos generados o refrendados por los aborígenes soberanos de las Pampas y Norpatagonia. En M. Bechis, Piezas de etnohistoria del sur sudamericano (pp. 361-378). Madrid: Colección América, CSIC.

Bechis, M. (2005 [2010]). La organización nacional y las tribus pampeanas en Argentina durante el siglo XIX. En M. Bechis, Piezas de etnohistoria y de antropología histórica (pp. 179-204). Buenos Aires: Sociedad Argentina de Antropología.

Bechis, M. (2010). Piezas de etnohistoria y de antropología histórica. Buenos Aires: Sociedad Argentina de Antropología.

Boccara, G. (2003). Fronteras, mestizaje y etnogénesis en las Américas. En R. Madrini, C. Paz (comp.), Las fronteras hispanocriollas del mundo indígena latinoamericano en los siglos XVIII-XIX. Un estudio comparativo (pp. 63-108). Neuquén, Bahía Blanca, Tandil: Universidad Nacional de Comahue, Universidad Nacional del Sur, Universidad Nacional del Centro de la Provincia de Buenos Aires.

Curiel, M. (1898). Guía histórica y estadística de Veinticinco de Mayo. Buenos Aires: El imparcial.

De Jong, I. y Ratto, S. (2008). Redes políticas en el área arauco-pampeana: la Confederación indígena de Calfucurá (1830-1870). Intersecciones en Antropología, 9, 241-260.

De Jong, I. (2008). Funcionarios de dos mundos en un espacio liminal: los “indios amigos" en la frontera de Buenos Aires (1856-1866). Revista CUHSO, 15(2), 75-95.

De Jong, I. (2011). Las alianzas políticas indígenas en el período de organización nacional: una visión desde la política de Tratados de Paz (Argentina 1852-1880). En M. Quijada (ed.), De los cacicazgos a la ciudadanía. Sistemas Políticos en la Frontera (pp. 70-130). Berlin: Ibero-Amerikanisches Institut Preussischer Kulturbesitz. 
Garavaglia, J. C. (2009). San Antonio de Areco, 1680-1880. Un pueblo de la campaña, del Antiguo Régimen a la modernidad argentina. Rosario: Prohistoria Ediciones.

Ginzburg, C. (2010a). El inquisidor como antropólogo. En C. Ginzburg, El hilo y las huellas. Lo verdadero, lo falso, lo ficticio (pp. 395-412). Buenos Aires: Fondo de Cultura Económica.

Ginzburg, C. (2010b). Microhistoria: dos o tres cosas que sé de ella. En C. Ginzburg, El hilo y las huellas. Lo verdadero, lo falso, lo ficticio (pp. 351-394). Buenos Aires: Fondo de Cultura Económica. Gregorio-Cernadas, M. (1998). Crítica y uso de las fuentes históricas relativas a la diplomacia indígena en la pampa durante el siglo XIX. Memoria Americana, 7, 61-89.

Gruzinski, S. (2007[1999]). El pensamiento mestizo. Cultura amerindia y civilización del Renacimiento. Barcelona: Paidós.

Havard, G. (2003). Cultural transfers, métissages, and mimetism in Franco-Indian North America. Coloquio Casa de Velázquez, Madrid. MS.

Infesta, M. E. (2006). La Pampa criolla: usufructo y apropiación privada de tierras públicas en Buenos Aires: 1820-1850. Mar del Plata: EUDEM.

Literas, L., Barbuto, L. (2014). El acceso a la tierra de los indios amigos. Un estudio comparativo de las tribus de Catriel y Rondeau (Buenos Aires, segunda mitad del siglo XIX). Seminario-Taller TEFROS. Homenaje a Martha Bechis, 21 y 22 de agosto, Río Cuarto, Argentina.

Literas, L. (2014). Itinerarios en las fronteras. La tribu de Rondeau y los orígenes del pueblo Veinticinco de Mayo: armas, parentesco y tierra (Argentina, siglo XX). Conferencia. Universitat Autònoma de Barcelona. 28 de febrero.

Quijada, M. (2011). La lenta configuración de una "Ciudadanía cívica" de frontera. Los indios amigos de Buenos Aires, 1820-1879 (con un estudio comparativo Estados Unidos-Argentina). En M. Quijada (ed.), De los cacicazgos a la ciudadanía. Sistemas políticos en la frontera, Río de la Plata, siglos XVIII-XX $\left(_{\text {pp. 149-308) }}{ }^{*}\right.$ Berlín, Ibero-Amerikanisches Institut.

Manara, C. (2010). Movilización en las fronteras. Los Pincheira y el último intento de reconquista hispana en el sur americano (1818-1832). Sociedad de paisajes áridos y semi-áridos, 2(2), 39-60.

Mandrini, R. (2006). Vivir entre dos mundos. Las fronteras del sur de la Argentina. Siglos XVIII y XIX. Buenos Aires: Taurus.

Ortelli, S. (2000) Marginalismo y relaciones interétnicas: blancos e indios en la frontera rioplatense en el siglo XIX. Revista Complutense de Historia de América, 26, 181-198.

Pavez Ojeda, J. (2008). Cartas mapuche: Siglo XIX. Santiago de Chile: Colibris \& Ocho Libros.

Pérez Zavala, G. (2005). Oralidad y escritura: los tratados de paz entre el Estado argentino y las tribus ranqueles. Tefros, 3. Disponible en: http://www.unrc.edu.ar/publicar/tefros/revista/ v3n1p05/completos/oralidad.pdf

Ratto, S. (2003). Cuando las "fronteras" se diluyen. Las formas de interrelación blanco-indias en el sur bonaerense. En R. Madrini, C. Paz (comp.), Las fronteras hispanocriollas del mundo indígena latinoamericano en los siglos XVIII-XIX. Un estudio comparativo (pp. 173-232). Neuquén, Bahía Blanca, Tandil: Universidad Nacional de Comahue, Universidad Nacional del Sur, Universidad Nacional del Centro de la Provincia de Buenos Aires.

Ratto, S. (2003). Una experiencia fronteriza exitosa: el negocio pacífico de indios en la provincia de Buenos Aires (1829-1852). Revista de Indias, LXIII (227), 191-222.

Ratto, S. (2005a). Caciques, autoridades fronterizas y lenguaraces: intermediarios culturales e interlocutores válidos en Buenos Aires (primera mitad del siglo XIX). Mundo Agrario, 5, 10. 
Ratto, S. (2005b). La lucha por el poder en una agrupación indígena: el efímero apogeo de los boroganos en las pampas (primera mitad del siglo XIX). Anuario de Estudios Americanos, 62(2), 219-249.

Ratto, S. (2007) Indios y cristianos. Entre la guerra y la paz en las fronteras. Buenos Aires: Editorial Sudamericana. Rojas Lagarde, J. L. (2013). Un chileno en la pampa bárbara: Francisco Iturra (1827-1859). Buenos Aires: Letemendia.

Ronda, J. (1994). Red-Head's Domain: William Clarck's Indian Brokerage. En M.C. Szasz (ed.), Between Indian and White worlds: the Cultural Broker (pp. 81-97). Oklahoma: University of Oklahoma Press.

Roulet, F. (2004). Con la pluma y la palabra. El lado oscuro de las negociaciones de paz entre españoles e indígenas. Revista de Indias, LXIV (231), 313-348.

Stolcke, V. (2006). Los mestizos no nacen, se hacen. En V. Stolcke, A. Coello (eds.) Identidades ambivalentes en América Latina (siglos XVI-XXI) (pp. 17-58). Barcelona: Bellatera.

Szasz, M.C. (1994). Introduction. En M.C. Szasz (ed.), Between Indian and White worlds: the Cultural Broker (pp. 3-20). Oklahoma: University of Oklahoma Press. Thill, J. P., Puigdomenech J. A. (2003). Guardias, fuertes y fortines de la Frontera Sur. Historia, antecedentes y ubicación catastral. Buenos Aires: Servicio Histórico del Ejército.

Villar, D. y Jiménez, J. F. (1997). Aindiados, indígenas y política en la frontera bonaerense (18271830). Quinto Sol, 1, 103-144.

Villar, D. y Jiménez, J.F. (2003). La tempestad de la guerra: conflictos indígenas y circuitos de intercambio. Elementos para una periodización (Araucanía y las Pampas, 1780-1840). En R. Madrini, C. Paz (comp.), Las fronteras hispanocriollas del mundo indígena latinoamericano en los siglos XVIII-XIX. Un estudio comparativo (pp. 123-171). Neuquén / Bahía Blanca / Tandil: Universidad Nacional de Comahue, Universidad Nacional del Sur, Universidad Nacional del Centro de la Provincia de Buenos Aires.

White, R. (2009 [1991]). The Middle Ground. Indians, empire, and republics in the Great Lakes region, 1650-1815. New York: Cambridge University Press.

Wolf, E. (2005 [1982]). Europa y la gente sin historia. México DF: Fondo de cultura Económica.

\section{NOTES}

1. Una versión preliminar fue presentada y discutida en el XI Congreso Argentino de Antropología Social (Universidad Nacional de Rosario, Argentina, julio de 2014) en la mesa “Agencias indígenas y políticas estatales en Argentina. Diálogos entre antropología e historia", bajo el título "Intersecciones entre agencias indígenas y políticas estatales. A propósito de José Valdebenito". Es parte de una investigación más amplia sobre la tribu boroga de Rondeau, realizada en el marco de los proyectos "Políticas indígenas y estatales en los espacios de frontera del extremo sur americano: Chaco, Pampa, Patagonia y Banda Oriental (siglos XVIII y XIX)" (Agencia Nacional de Promoción Científica y Técnica) y "De la sociedad de frontera a la consolidación nacional: actores sociales e identidades en la frontera sur argentina (siglo XIX)" (Universidad de Buenos Aires) dirigidos por la Dra. Ingrid de Jong; y durante una estancia en el grupo de investigación Antropologia i Història de la Construcció de les Identitats Socials i Polítiques, coordinado por las Dras. Verena Stolcke y Montserrat Ventura i Oller en la Universitat Autònoma de Barcelona. 
2. Valdebenito no fue el único. Por ejemplo, también lo hizo muy probablemente Juan de Dios Veloz quien desde entonces será el principal ladero de Valdebenito en la administración militar.

3. 28 de noviembre de 1830, Archivo General de la Nación [AGN], Secretaría Juan Manuel de Rosas [SJMR], Sala X, Caja 23-9-4, fs. 117-118.

4. 7 de octubre de 1833, Mariano Rondeau a Miguel Miranda. AGN, SJMR, Sala X, Caja 24-8-2, f. 47.

5. 21 de febrero de 1834, Juan Ignacio Cañuquir, Mariano Rondeau, Francisco Caneullan y Juan Jos é Melin a Juan Manuel de Rosas. AGN, SJMR, Sala X, Caja 24-9-1, f. 606-607.

6. 28 de febrero de 1834, Pablo Millalicán a Manuel Delgado. AGN, SJMR, Sala X, Caja 24-9-1, f. 699-700.

7. AGN, SJMR Sala X, Caja 43-1-3.

8. Una de estas acciones fue narrada por el propio Valdebenito, indicando a la comandancia de la frontera la necesidad de reconocer el destacado papel de los capitanejos borogas y las tropas indígeno-criollas. 21 de noviembre de 1847. Servicio Histórico del Ejército [SHE], Campaña contra los Indios, f. 433.

9. 28 de abril de 1852. AGN, Sala X, Caja 18-4-7, s/f; AGN, Sala III, Caja 260.

10. Archivo Histórico del Ejército [AHE], Legajo personal José Valdebenito.

11. En ese mismo diálogo evocado por Avendaño, el cacique Caniu-Calquim también hizo referencia a otros destacados intermediarios político-culturales de entonces: Manuel Baigorria y Francisco Iturra.

12. $1^{\text {o }}$ de junio de 1855. SHE, Campaña contra los Indios, s/f.

13. Actualmente este episodio es materia de análisis en un trabajo denominado "Poder y política en una tribu de indios amigos. La sublevación de Carri-llang (1852-1862)".

14. En ocasión de estas invasiones, el vecindario local y las autoridades militares de otros puntos de la frontera solicitaron al juez de paz de Veinticinco de Mayo que se organizasen expediciones punitivas al mando de Valdebenito.

15. 11 de noviembre de 1861. AGN, Sala X, 20-7-2, s/f.

16. AHE, Legajo personal José Valdebenito.

17. AGN, Sala III, Caja 281.

18. “Casas, Boreales, Atucha y otros. 1866". Archivo General de la Dirección de Geodesia de la Provincia de Buenos Aires [AGDGPBA] Mensuras, Veinticinco de Mayo, leg. 55.

19. 20 de diciembre de 1860 y 24 de febrero de 1862. Archivo de Veinticinco de Mayo [AVM], Administración de Justicia, Testamentarias, José Valdebenito.

20. Concesión de tierras a los capitanejos Martín, Francisco y Manuel Rondeau y su tribu. Provincia de Buenos Aires, Ley 512, 1 de octubre de 1867.

\section{ABSTRACTS}

This article analyzes the cultural brokers role as well as the intersections of the Indigenous agency and state policies in the Indian frontier during the nineteenth century in Argentina, in the political and military life of José Valdebenito. After fighting against the Chilean republicans during the war to the death (1819-1832), Valdebenito migrated to the Pampa with the Borogas, where they negotiated the peace with the government of Buenos Aires (1830). Valdebenito joined the army of Buenos Aires and was a lenguaraz (interpreter) for the Boroga chiefs (caciques). After that he advocated for the Boroga settling in Cruz de Guerra (Veinticinco de Mayo, Buenos Aires) 
under state jurisdiction, where he commanded Indigenous and Creole soldiers for more than 20 years until his death in 1859. These services and his kinship with the descendants of the chief Rondeau granted him a higher position in the local hierarchy and a significant leadership over the Borogas, to the point of being essential to explain the advance of the state frontiers in Veinticinco de Mayo.

A partir del itinerario político y militar de José Valdebenito, este artículo analiza el papel de los intermediarios interétnicos así como las intersecciones de las agencias indígenas y las políticas estatales en las fronteras, durante la extensa y polémica construcción estatal argentina (siglo XIX). Miembro de las montoneras realistas que combatieron a los republicanos chilenos durante la guerra a muerte (1819-1832), Valdebenito migró con los borogas a la Pampa, donde negociaron la paz con el gobierno de Buenos Aires (1830). Valdebenito se incorporó al ejército porteño y simultáneamente ejerció de lenguaraz entre el gobernador y los caciques borogas. Posteriormente intercedió a favor de la migración boroga bajo jurisdicción estatal en Cruz de Guerra (Veinticinco de Mayo, Buenos Aires), donde ejerció el mando militar de indígenas y criollos por más de 20 años - hasta su muerte (1859)-. Estos servicios y el parentesco con los descendientes del cacique Rondeau le valieron ascender en la jerarquía local y adquirir una notable ascendencia en los borogas, al punto de que su protagonismo es ineludible para explicar el avance de las fronteras estatales en el actual partido de Veinticinco de Mayo.

\section{INDEX}

Keywords: Southern frontier, Indios Amigos, Boroga, cultural brokers.

Palabras claves: frontera sur, indios amigos, borogas, intermediarios culturales

\section{AUTHOR}

\section{LUCIANO LITERAS}

Consejo Nacional de Investigaciones Científicas y Técnicas / Universidad de Buenos Aires, Facultad de Filosofía y Letras, Instituto de Ciencias Antropológicas, Sección Etnohistoria.

Argentina

Correo electrónico: lucianoliteras@gmail.com 